\title{
Use of Storage Technologies to select Knowledge Management Tools and Strategies for M-SMEs
}

\section{Uso de Tecnologías de Almacenes para seleccionar Herramientas y Estrategias de Gestión del Conocimiento para MiPyMEs}

\author{
Emilio Talamante-Lugo ${ }^{1 *}$ \\ Gerardo Sanchez-Schmitz ${ }^{1}$
}

Jose Luis Felix-Moreno ${ }^{1}$

Jose Luis Ochoa-Hernandez ${ }^{1}$
Carlos Ignacio Feuchter-Leyva ${ }^{1}$

Luis Felipe Romero-Dessens ${ }^{1}$

Recibido 22 de mayo de 2018, aceptado 20 de agosto de 2018.

Received: May 22, 2018 Accepted: August 20, 2018

\begin{abstract}
The Storage Technologies allow to have an effective and planned management of the resources a company contains (materials or information). When they contain information, there is a need to possess an information storage system, to retrieve relevant aspects from a data reservoir. Regarding Knowledge Management (KM) on Micro, Small and Medium Enterprises (M-SMEs) usually has short presence on the literature, which is why this project can help to collect information on the subject. This work will be considered to those people who support the recently open M-SMEs, which present difficulties on their intellectual capital, innovation and development, generating a high rate of failure. With the objective of effectively apply KM on those companies using data storages, this article consists on presenting the current situation on the studied elements in the introduction, following a theoretical analysis and the process designed to achieve the objective. The process was to develop a database, with a design based on Storage Technologies which was used, and its utility will be determined on the conclusions. As result, the objective was achieved because, with an amount of case studies, data of interest was available and formed a new criterion that allows a practical and integral selection of tools and strategies of KM on those companies.
\end{abstract}

Keywords: Intellectual capital, enterprises, practices, database system.

\section{RESUMEN}

Las tecnologías de almacenes permiten tener una gestión efectiva y planificada de los recursos que una empresa tiene (materiales e información). Cuando contienen información, existe una necesidad de poseer un sistema de almacenamiento de información, para recibir aspectos relevantes por parte de un almacén de datos. En el caso de la Gestión del Conocimiento (GC) en Micro, Pequeñas y Medianas Empresas (MiPyMEs) suele tener poca presencia en la literatura, por lo que este proyecto puede ayudar a recolectar información del tema. Este trabajo está dirigido a aquellas personas que apoyan a las MiPyMEs de nueva creación, las cuales presentan dificultades en su capital intelectual, innovación y desarrollo, generando un alto grado de fracaso. Con el objetivo de aplicar efectivamente la GC en dichas empresas mediante el uso de almacenes de datos, este artículo consiste en presentar la situación actual de los elemento

\footnotetext{
1 Universidad de Sonora. Departamento de Ingenieria Industrial. Hermosillo, México. E-mail: talamante.emilio@gmail.com; josel.felixmo@gmail.com; carlos.feuchter@hotmail.com; gsanchez@industrial.uson.mx; joseluis.ochoa@industrial.uson.mx; luisfelipe.romero@unison.mx

* Corresponding author: talamante.emilio@gmail.com
} 
de estudio en la introducción, siguiendo de un análisis teórico, el proceso diseñado para cumplir con el objetivo. El proceso trata del desarrollo de una base de datos, con un diseño en base a las tecnologías de almacenes, del cual se hace uso y se determina su utilidad en las conclusiones. Como resultado se cumplió el objetivo, ya que, a partir de un conjunto de casos de estudio, se tienen disponibles datos de interés, los cuales forman un nuevo criterio para que se haga una práctica e integra selección de herramientas y estrategias de GC en las empresas.

Palabras clave: Capital intelectual, empresas, prácticas, sistema de base de datos.

\section{INTRODUCTION}

Knowledge Management (KM) is one of the main strategies that allow companies to innovate and maintain competitive advantage. However, it is used to be applied on big companies, as they have implementation enablers such as technology, economic and employer resources. In the case of Micro, Small and Medium Enterprises (M-SMEs), especially those recently opened, there are little activities on this matter. That is the reason why this study has the goal of serving as guidance to those who want to work on KM applied on M-SMEs and have a base to select the tools and strategies of KM accurate for the company.

The data analysis consists on extracting information from a group of case studies about KM applied on SMEs. The information to extract will be the SME data, such as: name of the company, where it is located, its number of employees and incomes. Also, the tools and strategies used on it will be listed, and they will be classified according to a KM maturity model. Finally, any important notes like learned lessons or recommendations will be listed too. The obtained information will be inserted on a database, designed in a way the researcher can easily access the tools and strategies according the criteria he/she needs to implement in the M-SME of interest. The database will be required to request specific queries and a filter series, resulting on the information needed to work on the M-SME.

This study consists of 5 sections, which exposes the most relevant aspects of the study, being this one the first, with the intention of introducing the lector on the main contents. The second one presents the previous theoretical works, serving as foundation of the KM understanding, the M-SMEs characteristics and the case studies of application of storage technologies to control the information flow. The third section proposes a methodology to implement the project, according to a model which reflects the process to solve the issue. The fourth section consists of the development of the database system based on the methodology. The last one will describe a discussion of the results and the future research needed.

\section{THEORICAL ANALYSIS}

\section{Knowledge Management in M-SMEs}

Knowledge can be referred as information processed by comprehension and the individual's experiences [1]. It contains information that is available and can be used in making decisions and actions [2]. Knowledge in two dimensions - tacit and explicit [3]. Is suggested that knowledge is tacit if it is tied to the senses, experiences and intuition [4]. Explicit knowledge is characterized as transmittable in formal language and can be stored in information systems [5].

Knowledge management is the process of taking measures to have an effective use of assets to acquire strategic advantage [6]. The main objective of KM is to ensure vital information (knowledge) is properly identified, selected, organized, shared and published to help a firm to perform its operations and achieve its objectives [7].

Regarding most M-SMEs, they manifest as less experience organizations that do not have a defined strategy nor understating of how they take advantage of their knowledge assets, as oppose of the larger ones [8]. These enterprises can benefit from KM activities about employee development, innovation, customer satisfaction and organizational success, since they tend to place more emphasis than larger firms on the management of tacit knowledge as they usually don't have the resources to invest on advanced technologies [9]. The M-SME sector needs to acquire knowledge in order to implement successful strategies and improve its capabilities [10]. 
Often, M-SMEs must deal with specific challenges which strongly differ from those faced by big companies. However, it is quite common, to adopt techniques which have been tried and tested in big companies [11].

\section{Design of databases as a storage technology}

Database design is a complex decision-making process. Each element has many characteristics and performances required to make movement between parameters easier. To do an effective design, it is necessary to develop a tool for collecting, storing and processing large amounts of data. The most convenient tool to perform these tasks is a database [11]. They also state that during its design, it is necessary to use the most relevant data on the subject and establish their relations, which will allow to operate various types of data, such as dates, numbers, currency and text.

Extracting data from a wide database requires that complex queries should be built across different business objects, which can only be accomplished by database specialists. Using an operational system for decision support has become even more inefficient with today's increasing volume and complexity of data. For decision support, when real-time ad hoc complex queries are required for interactive analysis, a multidimensional structure that contains historical data, aggregates relevant information from various sources, and is maintained separately from operational databases is needed. This structure is known as a data warehouse. It is defined as the combination of technologies that facilitates and maintains the management of historical data provided from different sources [12].

The purpose of designing databases, thus, turned out to be how to acquire, classify, store, and analyze huge datasets and extract knowledge from them. Furthermore, the processing and the analysis of massive data has additional challenges, such as how to address this data, how to speed up the processing, and how to maintain the data veracity. To extract and process interest data, it is recommended to use the process known as Knowledge Discovery in Databases (KDD) process by which the data are selected, preprocessed, transformed, mined, and evaluated [13].

It is considered that creating a database is primarily preferred for complex domains if design involves a lot of domain experts and a group of analystdesigners [14], but as a result, a unified irredundant database scheme should be obtained. In addition, the database design is a continuous process: client needs, a detailed description of domain entities, their attributes and how those entities relate to each other.

\section{Database normalization}

Database normalization is a key process for designing databases. Normalization is a process that takes an existing database design that can have anomalies, errors o redundancies, and improves it by decomposing relations, based on a known set of dependencies. When the normalization is not applied, database systems are usually inefficient and inaccurate [15].

Relational database relationship must meet certain requirements, to meet the different paradigms that database design usually implies [16]. At the time of writing this article, there are six kinds of relationship database paradigm: the first normal form (1NF), the second normal form (2NF), the third normal form (3NF), BC normal form (BCNF), the fourth normal form (4NF), the fifth normal form (5NF) and the sixth Normal Form (6NF). To fulfill normal requirements, the $1 \mathrm{NF}$ is the minimum paradigm. Basing on the 1NF, further meeting more requirements is the $2 \mathrm{NF}$ and a higher-level paradigm. Fortunately, in practical design application, you normally only need to reach the $3 \mathrm{NF}$.

\section{Systematic Layout Planning}

Systematic Layout Planning (SLP) is a prominent procedural approach and is widely used in layout design for various small and medium enterprises, and although it's a bit of and older technique, recent works have been expanding it use to other areas of application because the advantages it offers as a layout design tool [17].

From another perspective, the restructuring of the layout is done to optimize the work process, always ensuring the security of the flow of materials, people and information [18].

SLP is a procedural layout design approach and is a relatively straight forward method that has been a proven tool in providing layout design guidelines [19], and although traditionally it has been used for designing facility layouts, the fact that it has 
been proven in practice makes it an ideal candidate to use for other applications where designing a layout it's the main desire. The more traditional application of SLP method is used to determine a reasonable production system layout scheme that is based on the analysis of a logistic relationship between blocks and operating unit relationships, then, uses a factor evaluation method to assess the schemes, and finally obtains an optimal scheme for the new layout.

There are three main steps in SLP: relationship diagram, Space relationship diagram and evaluation. The relationship diagram shows the importance of each department/ area with respect to each other. It includes logistics relationships diagram, non-logistics relationships and comprehensive relationships. When the goal is to achieve an effective layout, it needs to begin with an in-depth discussion of work relationships. In this case, the primary focus of the discussions surrounded the issue closeness. Each unit was related to every other unit in the system. In the relationship diagram, these closeness values were placed in the corresponding diamond. The closeness rating is shown in Figure 1 [20].

Fuente: Lin et al., 201320

\begin{tabular}{|c|c|c|c|}
\hline $\begin{array}{l}\text { Closeness } \\
\text { rating }\end{array}$ & Closeness & Line code & Value \\
\hline A & Absolutely necessary & $\overline{\overline{\equiv \underline{\underline{ }}}}$ & 4 \\
\hline $\mathrm{E}$ & Especially important & $\overline{\bar{\equiv}}$ & 3 \\
\hline I & Important & & 2 \\
\hline $\mathrm{O}$ & Ordinary closeness & & 1 \\
\hline $\mathrm{U}$ & Unnecessary & & 0 \\
\hline
\end{tabular}

Figure 1. Closeness rating table for SLP.

\section{Entity-Relationship Diagram}

To develop a conceptual data model, normally it involves analyzing the problem domain and coming up with a database diagram using the Entity-Relationship (ER) model. Once the diagram is designed, it is then converted into a relational schema before the actual database is created and implemented. However, although it may sound easy to map an ER diagram, it is not an easy task to perform, it is not as easy for a novice, as it needs to meet some requirements and it involves complex logical thinking [21].
For database design and system analysis purposes, the entity-relationship (ER) model and its accompanying ER diagrams (ERD) are the ones used [22]. ERD provides developers with an overall grasp of the data requirements, modeling and database structures of the information system before the implementation phase.

\section{METHODOLOGY}

This project will follow a specific process to use storage technologies by developing a database. Figure 2 presents a model of this process, which consists of 5 phases. The first one being establish the case studies relevant data, where, after selecting the ones to work with, define the characteristics required to make queries that output the needed data. Then, there will be a design of the Entity Relationship Diagram, which helps to declare what would be the tables name, their relation between them and their attributes. The third one defines the attributes characteristics, consisting on describing each setting requested by the system and their assigned values. Its development will be followed and finally, the data of the selected cases will be inserted on it.

The research type will be qualitative, with a descriptive reach. The qualitative research focuses on understanding the phenomena by getting a deep look in its area [23]. The study depends on the point of view of the researcher, and its objectives will be defined as the study progress. About the descriptive reach, it consists of describing context, events and phenomena. The properties and profiles are defined without telling the relationship between them.

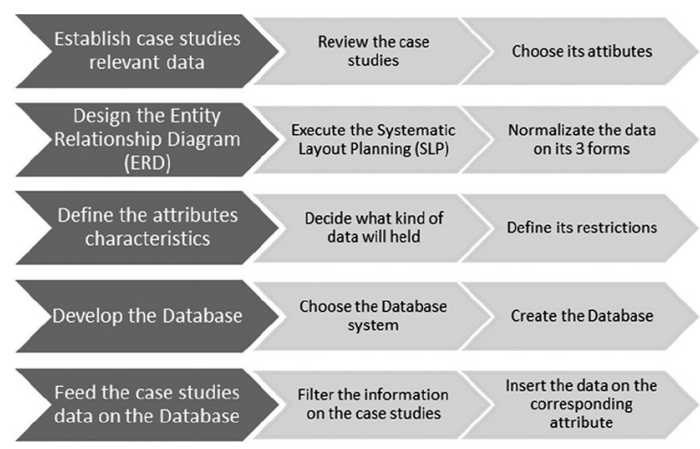

Figure 2. Research methodology model. 
Phase 1: Establish the case studies relevant data On this phase, after getting an amount of case studies of KM application on SMEs, an analysis will be realized to detect the principal and frequent characteristics presented on those. Those ones are the attributes. The attributes on the database represents the name of each column.

\section{Phase 2: Design the Entity Relationship Diagram (ERD)}

To design the ERD, first, the Systematic Layout Planning will be realized. This activity consists of assigning a value of each possible relation on a group of elements, and those elements will be the attributes. After the value assignation, the attributes will be aggrouped according of its most valuable relations, resulting in the definition of the entities, which are the tables name. Once defined, the 3 forms of normalization will be executed to get the appropriate relationships between each entity.

\section{Phase 3: Define the attributes characteristics}

Based on the ERD design and the requirements of the project, the Database attributes characteristics will be planned. Each attribute needs to have a type of input, the restrictions and if it is a primary key or not.

\section{Phase 4: Develop the database}

Once the ERD is ready and the attributes are well defined, the Database System will be chosen. The system works as the development environment, where the entities, their relationships, the attributes and their characteristics will be developed.

\section{Phase 5: Feed the case studies data on the Database} After the database structure is developed, it will be ready to be feed. Based on each case study, the required information will be extracted and inserted on their corresponding attribute, in a way where specific filters can be executed to get the required information.

\section{RESULTS}

Given the necessity of research about KM applied on M-SMEs, this project will develop a database of data extracted from case studies of the subject mentioned. By doing this, researchers will get many references of which KM tools have worked on enterprises like the ones he/she is working with. To accomplish this, the methodology explained on the previous chapter will be followed.

\section{Phase 1: Established case studies relevant data}

To get the relevant data, a series of case studies needed to be analyzed. They were selected by: the year of publication (last 10 years), indicators that define a SME (number of employees and years in the market), thematic (about KM, innovation or intellectual capital applied on SMEs), and the publishing company (a worldwide known journal). Those articles were read, where focus was on data that would let the reader know the actual state of the company regarding $\mathrm{KM}$, those being: the company KM practices such as tools, strategies, areas involved, lessons learned; and information regarding their key activities and characteristics. Table 1 indexes the characteristics considered to search on the journals database.

Table 1. Data to be extracted from case studies

\begin{tabular}{|l|l|}
\hline \multicolumn{2}{|c|}{ Aspects of interest to extract from case studies } \\
\hline Article name & Business activity \\
Year of publication & KM tools \\
Lessons learned & Company time on the \\
Name of the authors & market \\
Kind of business & KM areas \\
(product/services) & Number of employees \\
Publishing company & \\
\hline
\end{tabular}

\section{Phase 2: Design the Entity Relationship Diagram (ERD)}

The ERD will be design after establishing what will be the entities (tables), the attributes (columns names) and the relationship between entities. To determine the members of each element, the aspects defined on the previous phase will be aggrouped to find its common characteristic, and how they relate to each other. The aggrupation consists of using the relationship diagram and the distribution layout model adapted from the Systematic Layout Planning (SLP). The first one is created by assigning a closeness rating of relation between each characteristic, as shown in Figure 3.

After getting the relations, a distribution layout can be built, presented on Figure 4. By getting the characteristics with the maximum value together, 


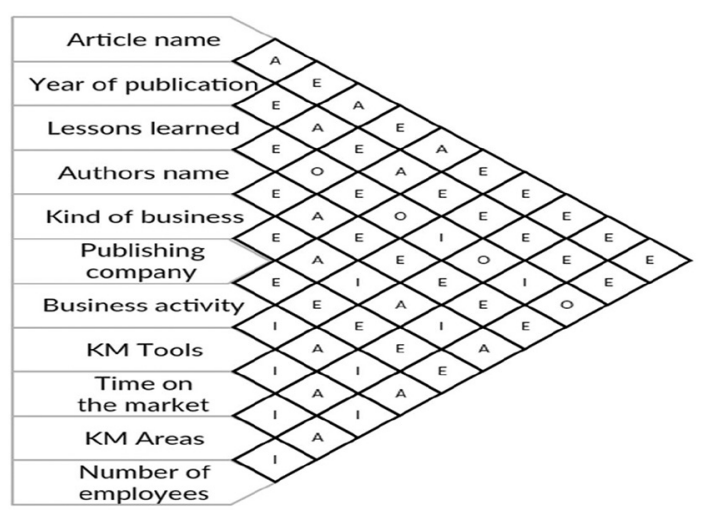

Figure 3. Relationship diagram with the closeness rating assigned in each pair of attributes.

a group was formed to represent those elements, resulting in 4 groups: KM practices, business, articles and lessons learned. The previous layout is the base to design the database. Since the attributes and entities are defined, a normalization is required to ensure the database won't present issues that could lead to data integrity loss. To normalize, the database must be in 3 different normal forms or "NF" (1NF, 2NF and 3NF).

The 1NF will be reached if none of the entities have rows with multiple values, so, the case study entity will be the link between the other 3 ones, by adding an attribute as primary key of "id_case_study" and declaring that this entity has a relationship of one-to-many with each of the rest of them, that means the case study can have many KM practices, business and lessons learned. Regarding $2 \mathrm{NF}$, it is necessary that a database non-key attributes depend only of one primary key and met the requirements of $1 \mathrm{NF}$. In that case, the Business entity gets a primary key called "id_business" and as KM practices as Lessons learned entities, they both have a composite primary key, being "id_case_study" the main one, and the other being "id_business". The 3NF has the requirement that there is not dependency between non-key attributes, which this database meets, because each entity non-key attributes depends only of one primary key. After the normalization and using the layout of Figure 3, the ERD results in the one shown in Figure 5.

\section{Phase 3: Define the attributes characteristics}

By getting a well-designed database, it is necessary to set every attribute in a way a database can work with. To make that happen, database systems ask the user for a series of options to select, which are described as:

- Column name: A name is assigned to the attribute, must be without spaces and if necessary, add a hyphen.

- Datatype (DT): The user must select from a variety of different data types as integers, Boolean, date or char. Most of them ask the user for the size of that variable, usually is by characters allowed.

- Is primary key (PK): Determines if the attribute acts as primary key or not.

- $\quad$ Not null (NN): Adds a condition of only accept cells when a non-null value is assigned.

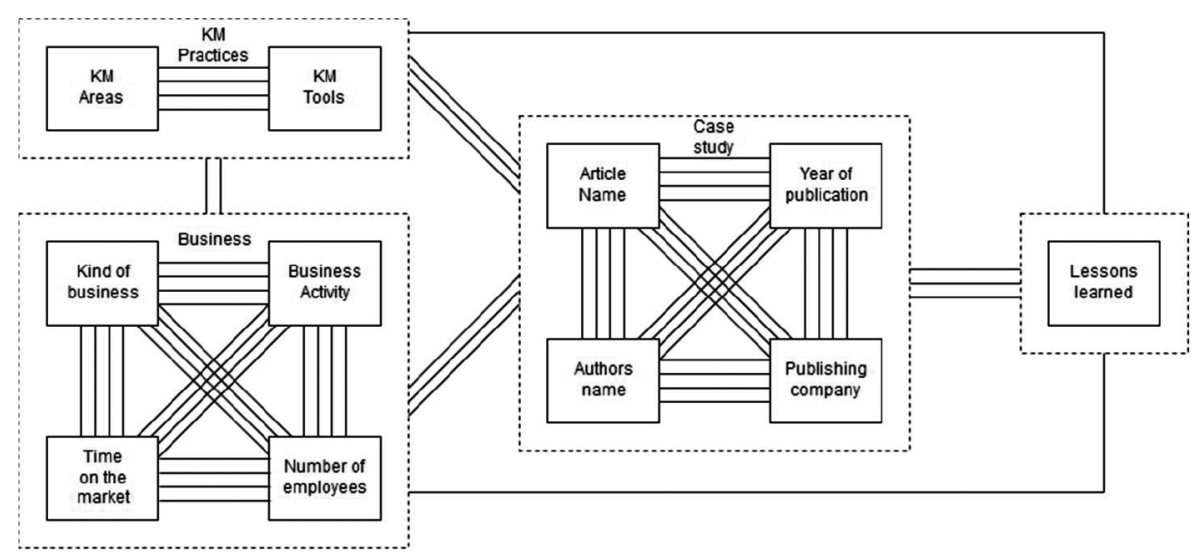

Figure 4. Distribution layout reflected on the closeness rating, by getting the attributes with the highest values closer and further the ones with the lowest. 


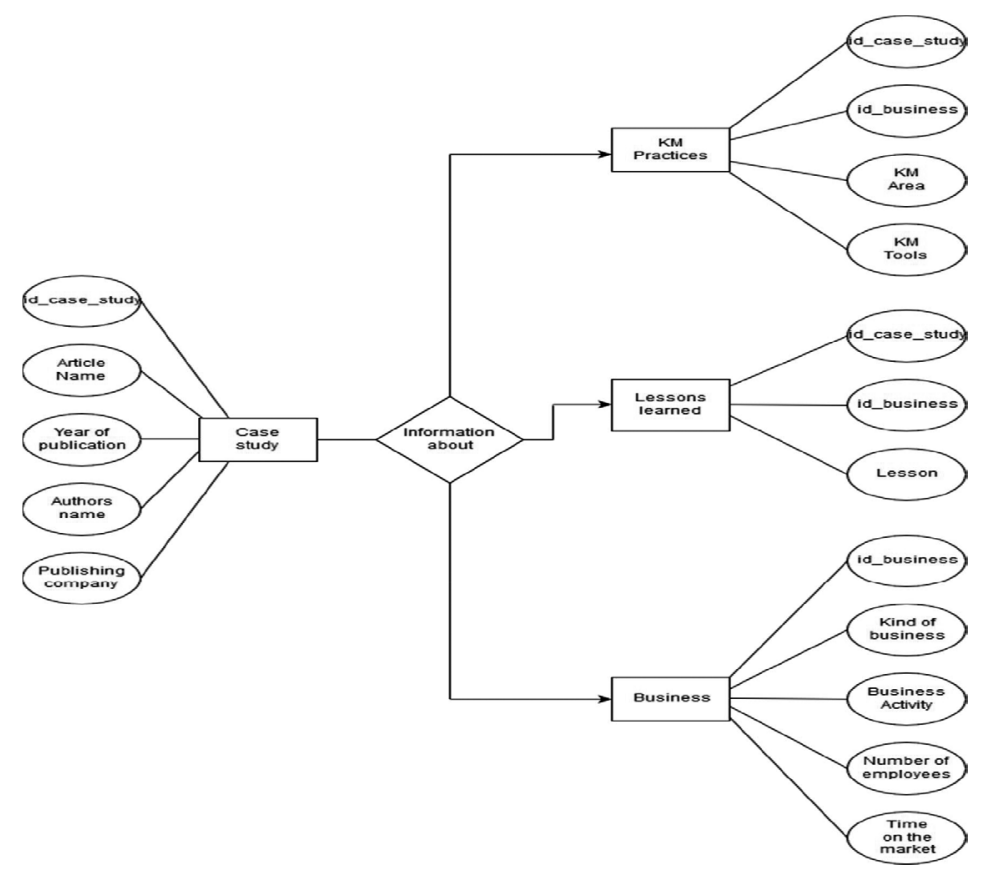

Figure 5. ERD designed for the database. Being the entities represented as rectangles, their attributes as ovals and their relations as diamonds.

- Unique index (UQ): Conditions each row to have a unique value.

- Is binary column (B): Determines if he char or varchar datatype will be binary or not.

- Is unsigned datatype (UN): Asks if the numeric datatype will allow negative numbers.

- Set "0" as default value (ZF): Assigns the value zero if not specified.
- Auto incremental (AI): For each row added, the corresponding value will be the consecutive.

- Generated column (G): All values on the column will be resulted from a command at creation.

- Default/Expression (D/E): The user enters the value assigned if there is not an assignment or, if the column is generated, the corresponding expression.

Table 2. Attributes and the options selected to define the values contained on each of them.

\begin{tabular}{|l|l|c|c|c|c|c|c|c|c|c|}
\hline \multicolumn{1}{|c|}{ Name } & \multicolumn{1}{c|}{ DT } & PK & NN & UQ & B & UN & ZF & AI & G & D/E \\
\hline id_case_study & $\operatorname{Int}(11)$ & $\mathrm{x}$ & $\mathrm{x}$ & $\mathrm{x}$ & & & & $\mathrm{x}$ & & \\
\hline article_name & $\operatorname{Varchar}(45)$ & & $\mathrm{x}$ & & & & & & & \\
\hline year_publication & $\operatorname{Int}(4)$ & & & & & & & & & null \\
\hline authors_name & $\operatorname{Varchar}(15)$ & & $\mathrm{x}$ & & & & & & & \\
\hline publishing_company & $\operatorname{Varchar}(15)$ & & & & & & & & & null \\
\hline km_area & $\operatorname{Varchar(20)}$ & & $\mathrm{x}$ & & & & & & & \\
\hline km_tool & $\operatorname{Varchar}(20)$ & & $\mathrm{x}$ & & & & & & & \\
\hline lesson & $\operatorname{Varchar}(45)$ & & & & & & & & & null \\
\hline id_business & $\operatorname{Int}(11)$ & $\mathrm{x}$ & $\mathrm{x}$ & $\mathrm{x}$ & & & & $\mathrm{x}$ & & \\
\hline kind_of_business & $\operatorname{Varchar}(10)$ & & $\mathrm{x}$ & & & & & & & \\
\hline business_activity & $\operatorname{Varchar}(20)$ & & $\mathrm{x}$ & & & & & & & \\
\hline number_employees & $\operatorname{Int}(3)$ & & & & & & & & & null \\
\hline time_on_market & $\operatorname{Int}(2)$ & & & & & & & & & null \\
\hline
\end{tabular}


Given the previous description, all attributes will be set by assign them the required options. Table 2 present the selected options, those will be the final setting to star developing the database.

\section{Phase 4 Develop the database}

Once the database is designed, a database system needs to be chosen. For this project, the selected system is MySQL, with a software called MySQL Workbench, version 6.3 CE. The system was chosen because there is more knowledge of its use in comparison with other systems and provides visual tools that facilitates the development. With the data presented on the previous phases, the database is created, with its model presented on Figure 6, where the entities were assigned, just as their attributes and those attributes that creates a link between two entities, selecting if that relation is one-to-one, one-to-many or many-to-many. Now that the database is set, the data extracted from case studies will be inserted on it.

\section{Phase 5: Feed the case studies data on the Database} Based on the criteria defined on phase 1 and 25 case studies which met the requirements, data were extracted from them and then inserted on the corresponding attributes fields. With the database and its data ready, the researcher can now make queries with the conditions he/she consider fit to receive the required data without getting repeated rows or empty fields. Figure 7 shows an example of one query, which requests the article name, the business activity, the KM tools and the KM area where the tool belongs, under a condition where the KM area value must be "Knowledge Sharing".

\section{CONCLUSIONS}

When working in applying KM on M-SMEs, knowing what tools or practices were needed to implement was a difficult task, since the researched had to go through a research in order to get data to reference on each company to work with. With this project, by designing and developing a database of KM practices applied on SMEs, it works as a solution of the lack of resources in literature, as it allows the researcher to get in a more accessible way, data of interest to form a better criterion to choose what to implement.

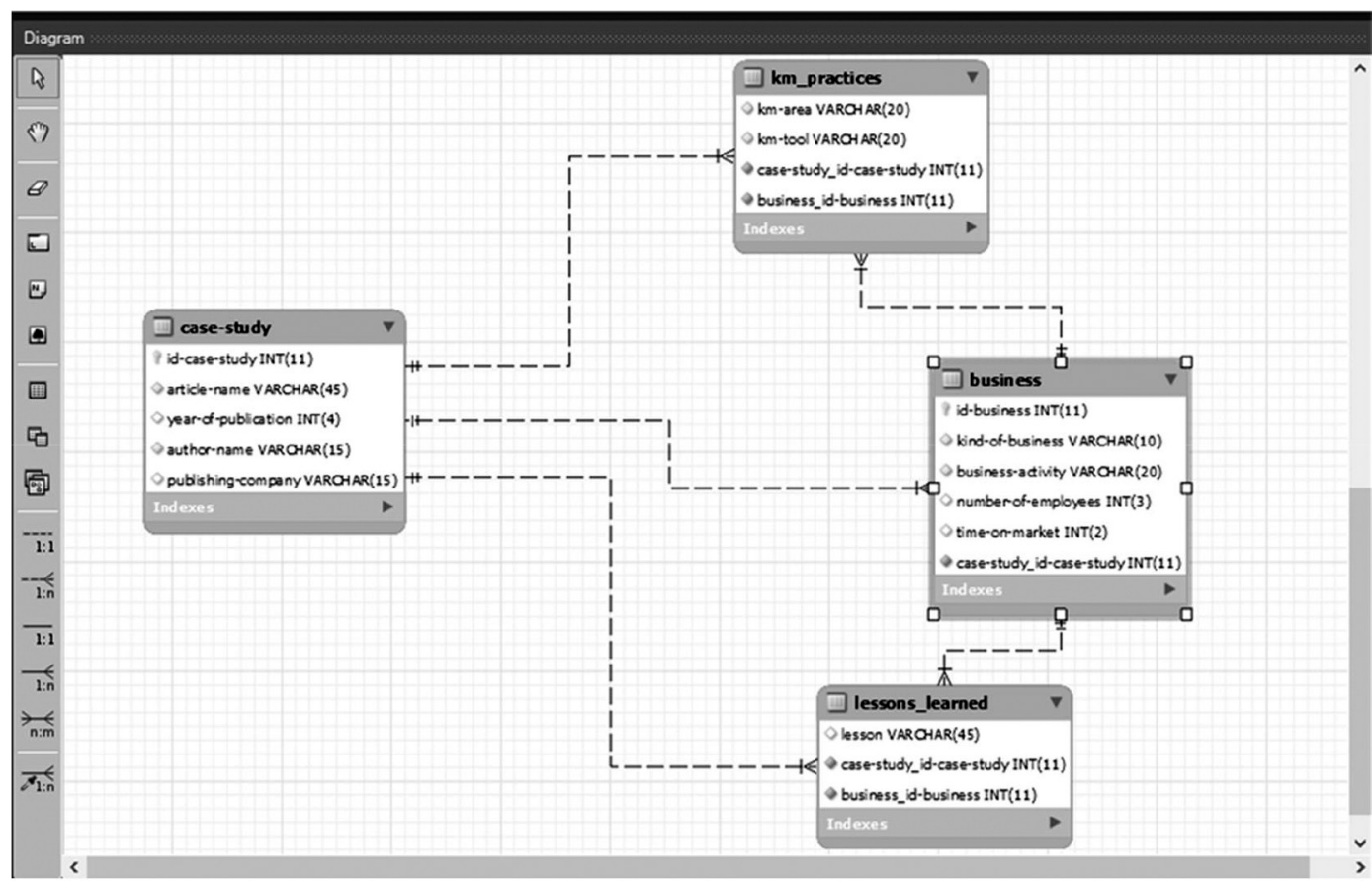

Figure 6. Database diagram produced from its design on MySQL Workbench, where the entities with their attributes and relationships are exposed. 


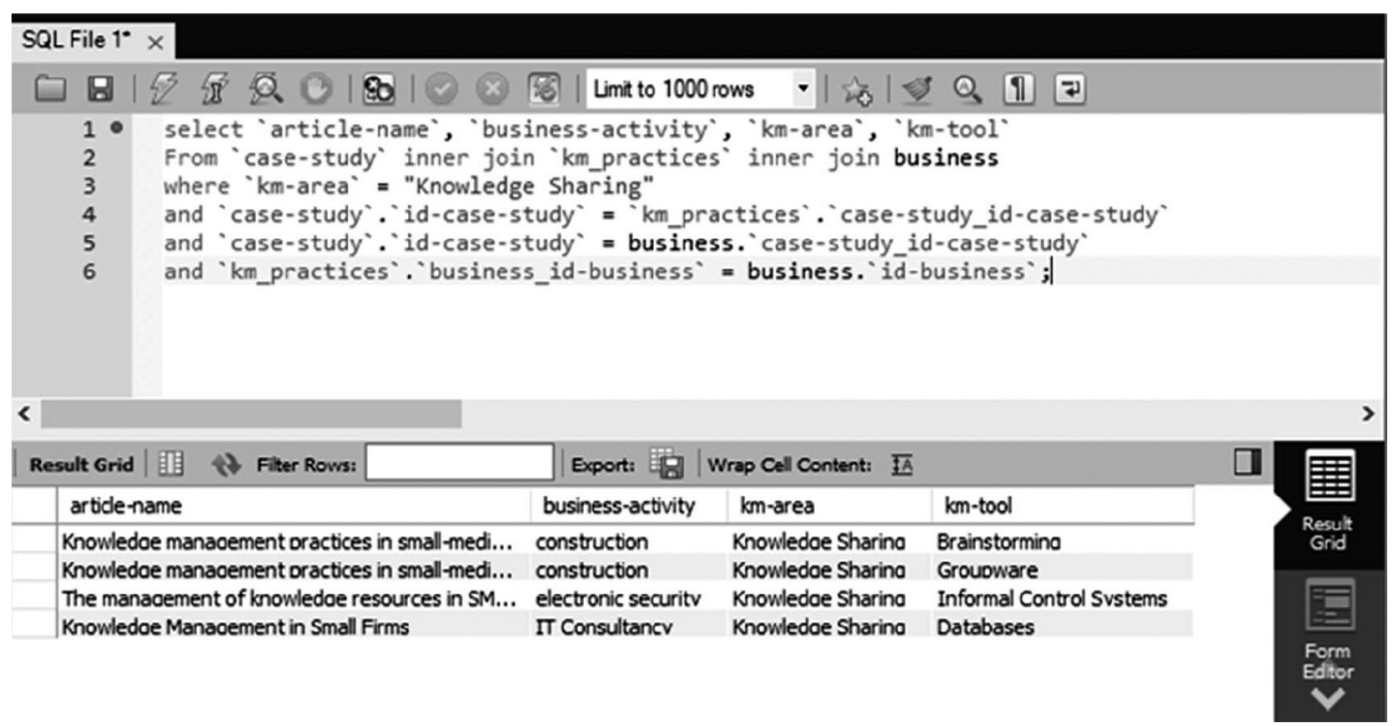

Figure 7. SQL query example to acquire selected attribute values under a given condition.

All the gathered data of KM practices serves as reference, because the tools and strategies mentioned on the case studies has been proved that they work. So, if the companies of interest are related to some of those reference, then the practices can be implemented, and the KM applied will support on the innovation and development of their intellectual capital, all in order to overcome the corresponding difficulties on each one.

It is recommended to use this database in a Web Application, and host so it can be available to everyone interested. With this, the application will work as a base of references where researchers can use as justification of why he/she used some KM tool to apply in a SME. And, as a web application, the researcher can access remotely and add new cases, resulting in a database which its data will be increasing as time passes.

\section{ACKNOWLEDGEMENTS}

To the co-authors on this work, the National Council of Science and Technology, and the University of Sonora.

\section{REFERENCES}

[1] M.A. Wibowo and R. Waluyo. "Knowledge management maturity in construction companies". Procedia Engineering. Vol. 125, pp. 89-94. 2015.

[2] C. Chang and T. Lin. "The Role of Organizational Culture in the Knowledge Management Process". Journal of Knowledge Management. Vol. $19 \mathrm{~N}^{\circ} 3$, pp. 433-455. 2015.

[3] M. Al-Qdah and J. Salim. "A Conceptual Framework for Managing Tacit Knowledge through ICT Perspective". Procedia Technology. Vol. 11, pp. 1188-1194. 2013.

[4] H. Zaim, O.F. Gürcan, M. Tarim, S. Zaim and L. Alpkan. "Determining the Critical Factors of Tacit Knowledge in Service Industry in Turkey". Procedia - Social and Behavioral Sciences. Vol. 207, pp. 759-767. 2015.

[5] R. Borges. "Tacit knowledge sharing between IT workers: The role of organizational culture, personality, and social environment". Management Research Review. Vol. $36 \mathrm{~N}^{\circ} 1$, pp. 89-108. 2013.

[6] M.S. Nawaz, M. Hassan and S. Shaukat. "Impact of Knowledge Management Practices on Firm Performance: Testing the Mediation Role of Innovation in the Manufacturing Sector of Pakistan". Pakistan Journal of Commerce and Social Sciences. Vol. $8 \mathrm{~N}^{\circ} 1$, pp. 99-111. 2014.

[7] V. Naicker, S. Le Roux and J. Bruwer. "Knowledge Sharing as a Value-Adding 
Initiative for South African SMME Sustainability: A Literature Review". Expert Journal of Business and Management. Vol. 5 $\mathrm{N}^{\mathrm{o}}$ 2, pp. 51-60. 2017.

[8] R. Cerchione and E. Esposito. "Using knowledge management systems: A taxonomy of SME strategies". Vol. 37, pp. 1551-1562. 2017.

[9] Edvardsson and S. Durst. "Does Knowledge Management Deliver the Goods in SMEs?". Business and Management Research. Vol. 2 $\mathrm{N}^{\circ} 2.2013$.

[10] S.M. Suarez-Ortega, A.M. Garcia-Cabrera and G. Knight. "A Model of Knowledge Acquisition for Developed Economies SMEs First Entering a Developing Economy". Procedia Economics and Finance. Vol. 23, pp. 33-37. 2015.

[11] M. Jacyna, P. Go, and K. Lewczuk. "Functions, relations and basic elements of database for the designing of storage facilities". 2017.

[12] Y. Leo. "Data Warehouse with Big Data Technology for Higher Education". Procedia Computer Science. Vol. 124, pp. 93-99. 2017.

[13] J.C.F. Silva, T.F.M. Carvalho, M.F. Basso, M. Deguchi, W.A. Pereira, R.R. Sobrinho, P.M.P. Vidigal, O.J.B. Brustolini, F.F. Silva, M. Dal-Bianco, R.L.F. Fontes, A.A. Santos, F.M. Zerbini, F.R. Cerqueira and E.P.B. Fontes. "Geminivirus data warehouse: a database enriched with machine learning approaches". BMC Bioinformatics. Vol. 18 $\mathrm{N}^{\mathrm{o}}$ 1, pp. 240. 2017.

[14] V.V. Osipova, I.L. Chudinov and A.S. Seidova. Formalized approach in relational database design. Vol. 685. 2016.

[15] H.I. Piza-Dávila, L.F. Gutiérrez-Preciado and V. H. Ortega-Guzmán. "An educational software for teaching database normalization". Comput. Appl. Eng. Educ. No July 2016. pp. 812-822. 2017.
[16] C.X. Ma and Y.M. Wang. "Application of the Standardization of the Relationship in the Database Design". Appl. Mech. Mater. Vol. 401-403, pp. 1809-1812. 2013.

[17] S.A. Ali Naqvi, M. Fahad, M. Atir, M. Zubair and M.M. Shehzad. "Productivity improvement of a manufacturing facility using systematic layout planning". Cogent Eng. Vol. $3 \mathrm{~N}^{\mathrm{o}}$ 1. 2016.

[18] M. Flessas, V. Rizzardi, G.L. Tortorella, D. Fettermann and G.A. Marodin. "Layout performance indicators and systematic planning". Br. Food J. Vol. 117 No 8, pp. 20982111. 2015.

[19] K.H. Liu, S.L. Hwang, M.H. Hsieh, S.F. Max Liang and C.F. Chuang. "Systematic layout planning in human-system interface: An evaluation of alarm displays with spatial proximity for accidents diagnosis of advanced boiling water reactor". Int. J. Ind. Ergon. Vol. 51, pp. 30-42. 2016.

[20] Q.L. Lin, H.C. Liu, D.J. Wang and L. Liu. "Integrating systematic layout planning with fuzzy constraint theory to design and optimize the facility layout for operating theatre in hospitals". J. Intell. Manuf. Vol. 26 $\mathrm{N}^{\circ}$ 1, pp. 87-95. 2013.

[21] L. Yang and L. Cao. "The Effect of MySQL Workbench in Teaching Entity-Relationship Diagram (ERD) to Relational Schema Mapping". Int. J. Mod. Educ. Comput. Sci. Vol. $8 \mathrm{~N}^{\mathrm{o}}$ 7, pp. 1-12. 2016.

[22] N.E. Cagiltay, G. Tokdemir, O. Kilic and D. Topalli. "Performing and analyzing nonformal inspections of entity relationship diagram (ERD)”. J. Syst. Softw., Vol. 86 No 8, pp. 2184-2195. 2013.

[23] R. Hernández-Sampieri, C. Fernández-Collado and M.P. Baptista-Lucio. "Metodología de la Investigación”. Editorial McGraw Hill. Sexta edición. CDMX, México. 2014. 